\title{
Patients' Views: Peer Support Worker On Inpatient Wards
}

\author{
Dr Joy M Rooney
}

Worcestershire Health and Care NHS Trust, Keith Winter House, 214A Stourbridge

Road, Catshill, Bromsgrove B61 0DJ Joy.Rooney@nhs.net

Nadine Miles

Honorary psychology student on placement from Worcester University c/o Keith Winter House

\section{Dr Tom Barker}

Worcestershire Health and Care NHS Trust, Studdert Kennedy House, Spring Gardens, Worcester WR1 2AE

\begin{abstract}
Purpose: To explore patients' experiences of intentional mental health peer support (PS)

Design/methodology/approach: Seven in depth interviews were carried out by an independent researcher with individual inpatients who volunteered via a PS worker following leaflet and poster distribution explaining the research on the two wards. Each recorded interview of thirteen questions was transcribed verbatim by the researcher and analysis identified common themes across the interviews.

Findings: An overarching theme of communication with patients was identified together with six main themes: person centeredness, practical support, building connections, emotional support, modelling hope, and recovery interventions. There were no negative comments expressed by interviewees.

Research limitations/implications: Small scale qualitative research allows in-depth exploration of experiences which is valuable in informing the further development of peer support.

Originality/value: There are very few published reports of inpatient experiences of peer support in inpatient settings.

Type: Research Paper
\end{abstract}

Keywords: mental health, peer support, evaluation, inpatient, service users, consumer, qualitative research.

There continues to be conflicting evidence in the more recent literature that peer support benefits patients/ service users/ consumers. From the comparison of randomised control trials (RCTs) either no effects, or slight non-significant benefits are reported although the emphasis of these findings seems to depend on the type of journal in question making the report: a psychiatric type journal making the emphasis in the negative (Lloyd-Evans et al., 2014; Pitt et al. 2013) versus a social psychiatric type (Fuhr et al, 2014). However, Lloyd-Evans et al. (2014) do suggest there was some evidence was associated with the positive effects of hope, recovery and empowerment beyond the end of the intervention, although this was not 
consistent within or across different types of PS. And Pitt et al. (2013) suggested that there was less emergency access to services. Other RCTs (Cook 2011, 2012; Daniels et al., 2013; Druss et al. 2010; Sledge et al. 2011 all show a small positive effect of PS. Fuhr et al. (2014) demonstrated a small positive effect on the quality of life and hope in high income societies with PS of those with serious mental health issues. And Chinman and Daniels (2014) are also more positive in their review of RCTs and feel with greater specificity, consistency, and rigor the evidence would be strengthened. When studying the transition between hospital and community, Simpson et al. (2014) found no differences between PS and standard treatment, except a hopelessness assessment - there was a lower score when PS workers were involved. Wrobleski et al. (2015) again found no differences, however the sample size was so small it would be impossible to find a statistically significant difference with such high confidence intervals.

The qualitative evidence on any benefits or otherwise of PS is more prolific. Repper and Carter (2011) were the first to review these and cite empowerment, social support and social functioning, empathy and acceptance, reducing stigma and hope as all contributing to the success of PS workers than professionally qualified staff in promoting hope and belief in the possibility of recovery, empowerment, and increased self-esteem, self-efficacy and self-management of difficulties and social inclusion, engagement and increased social networks. Repper and Watson (2012) demonstrated the benefit of PS via an inpatient text when being given a combination of recovery, practical and emotional support "You have been such a good friend to me, I don't know what I would have done without you".

Walker and Bryant (2013) report on four qualitative evaluations of PS and describe PS workers as role models, with increased hope, motivation and social networks when working with PS workers (PSWs), building rapport with PSWs more easily than with healthcare professionals and also that PSWs were "street smart", although the role model theme was disputed by some articles. Lawton-Smith (2013) reports on themes such as empathy of PSWs, open and trusting relationships which they may not get from professional staff, a focus on empowerment, helping to develop selfefficacy and self-esteem and on giving people hope, vital to their recovery. Roberts and Boardman (2014) from systematic reviews suggest that PS reduces readmissions, enhances community integration, increases confidence, self-esteem, empowerment, practical help and guidance, and challenging stigma and discrimination. Kelly et al. (2014) demonstrated through the BRIDGE intervention that peer navigators keep service users out of emergency services rather they attend GP primary care. Gidugu et al. (2015) interviewed 19 community users of PS in USA and concluded that the mechanisms of action of PS were through traditional helping relationships such as practical support, role modeling, mentoring and social opportunities alongside getting emotional support through a normalizing relationship with someone with similar experiences.

When it comes to patients' evaluation of PS in inpatient settings the evidence is more limited (Bouchard et al. 2010; Faulkner and Basset, 2010; Ockwell et al, 2012). Bouchard et al. (2010) studied informal PS on an inpatient ward and all outcomes were judges as beneficial. Such benefits were listed as improved emotional state, behaviour and outlook on their current situation and examples and quotes given. 
Faulkner and Basset (2010) held focus groups with 52 participants from five community organizations with questioning around - what does PS mean to you? What are the benefits and challenges of PS and what have you to gain from PS? Their resulting themes can be summarized as: shared identity, increased selfconfidence, the development and sharing of skills, improved mental health and wellbeing, accompanied by less use of mental health and other services, an increased role information sharing and signposting, a feeling that PS challenges stigma and discrimination, for those involved in giving one-to-one and more formal PS there was also the benefit gained from helping others.

Ockwell (2012) evaluated the work of an independent organisation (PROSPECT) working within an inpatient setting on a snapshot day and 18 out 54 ie one third were spoken to by PSWs while only one patient had not found PSW helpful.

Finally, the Nesta (2015) report of 1000 references demonstrates that PS across many health issues is of some benefit, however, they conclude that further study is needed. Furthermore, a call for more research on assessing the impact of PS on service users was made by Mahlke et al. (2014). The purpose of this study is to determine whether or not the patients themselves believe that PS is beneficial whilst on inpatients' wards. The settings used are Worcestershire Health and Care NHS Trust Holt and Keith Winter House. The former is and acute ward whilst the latter a recovery unit.

\section{Method}

Patients were invited to participate in an in-depth and semi-structured interview via posters and a leaflet. Those that were interested let staff and the PS worker know. Eight participants were recruited, four female and four male, however, one female patient pulled out due to ill health during the data collection process.

The interviews were conducted by a $3^{\text {rd }}$ year undergraduate BSc Psychology student from the University of Worcester. The interviewer was female with previous mentoring and counselling training, no prior relationship had been established between the interviewer and interviewees before the evaluation had commenced. The PS worker introduced each patient to the interviewer and the interviewer introduced herself to the interviewees as an honorary psychology assistant interested in the views and experiences of the patients in relation to the PS they had received. Patients had sufficient capacity to understand the anonymity of their interview and two of the eight returned a signed Trust form to allow quotes to be used for the purposes of anonymous publication.

Participants were guided through thirteen open-ended questions adapted from McLean et al (2009) and the interviews were recorded.

Each interview was transcribed verbatim by the honorary psychology assistant and highlighted excerpts of text that portrayed an idea coded by participant number and transcription line number(s). The authors read and reread the scripts and agreed/ disagreed/ added to these excerpts independently; this resulted in 58 agreed excepts. Overarching theme, themes and sub-themes were then independently derived from those ideas which appeared most frequently and agreed during 
authors' meetings Participant quotations, identified with a participant and line number, are presented to illustrate the themes.

\section{Key Findings}

The overarching theme was that of communication with patients. Within this, six themes and up to seven sub-themes were identified as shown in the thematic map of service users' experiences of PS (Figure 1). These are person-centeredness, practical approach, building connections, emotional support, modelling hope and recovery interventions.

It was not possible to ask the patients what they thought of the thematic analysis as they have moved on to community settings.

Person-centeredness referred to the way the interviewees spoke about the peer worker being interested in them as people, as being informal, looking forward to being engaged and understanding of the issues of having a period of poor mental health in general.

"She isn't patronising and she doesn't talk illness I know that sounds really strange but she actually doesn't talk about diagnoses and she's never asked me what my diagnoses is because it doesn't really matter to her." (P1: 45-48)

Practical support was chosen as the second theme as examples of this were given for most patients. Patients spoke about all those things that they could not do while on the ward that they were assisted with.

"Getting to the dentist. I was under section at the time so I couldn't manage to get to the dentist and it had taken them three weeks to get me an emergency dental appointment." (P1: $10-12)$

Building connections was about regaining the confidence to interact more with other people, beginning with the PS worker. Patients spoke about how sharing lived experience was useful and it was just helpful to have someone to talk to.

"When I came here I didn't have much contact with friends or people outside I actually found it difficult to contact people from outside so, having someone here that had been through a similar kind of situation I felt very appreciative of her." (P4: 20 26)

Emotional support referred to the way interviewees spoke about relying on someone to carry patients' wishes forward.

Participants spoke about the non-judgmental support that they received from PSW, and, how having lived experienced helped them to be more understanding:

“The peer worker didn't speak on my behalf at all and she didn't interfere or offer her opinion it just was what it was that she was there to support me if I needed her support." (P1: 101-103) 
Many interviewees spoke of modelling hope as looking forward to a better future outside the confines of mental ill-health. Participants spoke about how useful it was to know that others have been through similar experiences

"I know that we've all got our own reasons why we are here but having someone having gone through that really helps." (P4: (38 - 42)

Recovery interventions were those face to face support, groups and training which will result in changes in outlook on life and allow patients to follow their hopes, dreams and aspirations. Patients spoke favorably of the time they spent with the PSW during interventions.

"Yeah, interesting she kind of drip feeds you so you get little bits to read and then if I have like a discussion around that and she's got like some case studies of other people's recovery which she's given me today. I found that was quite useful that maybe there are similar people to me that have had similar experiences." (P1: 29 32)

There were no negative comments about the PSW's throughout the data, although a suggestion was made as to how the PSW's could raise patients' awareness of this service such as: having comments displayed in the ward that highlight the service users' experiences of PS, and, how the PS intervention could be of use to them. Other comments made were that some of the service users tended to prefer and find the face to face support more beneficial to them rather than the group work.

\section{Discussion}

How patients' experienced intentional mental health PS is examined in this small qualitative study; such inpatient studies are rare. None have produced similar thematic results although Bouchard et al (2010) cited improved emotional state for informal PS and emotional support is a theme recognised in this study. While Gidugu et al. (2015) also think emotional support important in community settings through a normalizing relationship with someone with similar experiences as do Repper and Watson (2012).

Emotional support can be described as informing, advocacy, inspiring and empowering (Figure 1). Repper and Carter (2011), Lawton-Smith (2013) and Robert and Boardman (2014) in their reviews all describe empowerment as an important theme across the whole spectrum of PS.

Although not widely reported the theme of person-centeredness is implicit in the reviews of Repper and Carter (2011), Walker and Bryant (2013), Lawton-Smith (2013) and Roberts and Boardman (2014) and being non-judgmental, a sub-theme (Figure 1) is advocated by Repper and Carter (2011). The other sub-themes of being informal, engaging, understanding, a non-pathological approach make up person-centeredness and together with accepting as cited in Repper and Carter (2011) makes this a term which can be used to remove any conflict when mentioning the recovery versus the medical model.

Practical support is a theme that is often mentioned in PS particularly in community 
settings (Gidugu et al 2015) and by Repper and Watson (2012) in an inpatient setting. Examples of practical support in this study are given in Figure 1, are not exhaustive and a snap-shot from the inpatients interviewed. There are sometimes conflicts between how much practical support can be given, other functions of a PSW and time constraints.

Building connections is placing emphasis on gaining self-confidence by communicating with the peer and is a new concept produced here. However, the sub-themes - sharing experiences is cited by Gidugu et al. (2015); while genuine empathy is mentioned as being important in Repper and Carter (2011) and LawtonSmith (2013).

Modelling hope through social networking, acknowledgement, and friendship is widely reported (Repper and Carter, 2011; Walker and Bryant, 2013 and LawtonSmith, 2013). This is because hope is one of the most important tenets in the ethos of recovery.

Recovery interventions are widely used in PS (Faulkner and Basset, 2010; Repper and Watson, 2012), although they differ between organisations. Only two of those on offer in inpatient settings were given by patients - bite size psychology and early warning signs which they felt were accessible and help to build a social community (Figure 1).

Faulkner and Basset (2010) demonstrated, from focus groups of community organisations, that face to face support and more formal PS benefited service users and this too is demonstrated here. Reports from the seven participants did not suggest that PS was unimportant to them unlike the one-day snapshot of 18 patients reported by Ockwell (2012) when one patient did not feel PSWs helpful.

Randomised control trial studies provide information on large amounts of numerical data rather than the qualitative opinions and perceptions of groups of people. RCTs are useful to statistically prove or disprove hypotheses but can also show indications and trends of effects of PS workers on the service uses, patients or consumers that experience their service. Those considered demonstrate that overall PS may be beneficial. However, qualitative studies such as the one presented here, are useful to define themes which can then be used to generate hypotheses to test in larger scale studies.

\section{References}

Bouchard, L., Montreuil, M. and Gros, R. N. (2010), "Peer Support among Inpatients in an Adult Mental Health Setting", Issues in Mental Health Nursing, Vol. 31 No. 9, pp. 589-598. DOI: 10.3109/01612841003793049

Cook, J. A. (2011) "Peer-delivered wellness recovery services: from evidence to widespread implementation" Psychiatric Rehabilitation Journal, Vol. 35 No 2 pp. 8789. http://dx.doi.org/10.2975/35.2.2011.87.89

Chinman, M. and Daniels, A. S. (2014), "Peer Support Services for Individuals With 
Serious Mental Illnesses: Assessing the Evidence", Psychiatric Services, (Washington, D.C.), DOI: 10.1176/appi.ps.201300244

Daniels, E. D., Cate, R., Bergeson, S., Forquer, S., Niewenhous, G. Epps, B. (2013), "Level-of-Care Criteria for Peer Support Services: A Best-Practice Guide" Psychiatric Services In Advance, Vol. 64 No. 12, pp. 1-3 doi: 10.1176/appi.ps.201300277

Druss, B. G. Zhao L. von Esenwein S. A., Bona, J. R., Fricks, L., Tucker, S. J., Sterling, E., DiClemente, R and Lorig, K. (2010), "The Health and Recovery Peer (HARP) Program: a peer-led intervention to improve medical self-management for persons with serious mental illness" Schizophrenia Research, Vol. 118 No. 1-3, pp. 264-270. http://dx.doi.org/10.1016/j.schres.2010.01.026

Faulkner, A. and Basset, T. (2010), A Helping Hands: consultations with service users about peer support. Together For Mental Wellbeing, London.

Fuhr, D.C., Salisbury, T. T., De Silva M. J.,Atif, N., Ginneken , N. V., Rahman, A. and Patel, V. (2014), "Effectiveness of peer-delivered interventions for severe mental illness and depression on clinical and psychosocial outcomes: a systematic review and meta-analysis", Social Psychiatry Psychiatric Epidemiology, Vol. 49 No.11, pp. 1691-1702. DOI 10.1007/s00127-014-0857-5

Gidugu, V., Rogers, E. S.., Harrington, S., Maru, M., Johnson, G., Cohee, J. and Hinkel, J. (2015), "Individual Peer Support: A Qualitative Study of Mechanisms of Its Effectiveness", Community Mental Health Journal, Vol. 51 No. 4, pp. 445-452. DOI $10.1007 / \mathrm{s} 10597-014-9801-0$

Kelly, E., Fulginiti, A., Pahwa, R., Tallen, L., Duan, L. and Brekke, J. S. (2013), "A Pilot Test of a Peer Navigator Intervention for Improving the Health of Individuals with Serious Mental Illness", Community Mental Health Journal, Vol. 50 No. 4, pp.435 446. DOI 10.1007/s10597-013-9616-4

Lloyd-Evans, B., Mayo-Wilson, E., Harrison, B., Istead, H., Brown, E., Pilling, S., Johnson, S. and Kendall, T. (2014), "A systematic review and meta-analysis of randomised controlled trials of peer support for people with severe mental illness", BMC Psychiatry, Vol. 14 No. 39, pp. 1-12 http://www.biomedcentral.com/1471$244 X / 14 / 39$

Lawton-Smith, S (2013). Peer support in mental health: where we today? The Journal of Mental Health Training, Education and Practice, Vol. 8 No. 3, pp. 152-158 DOI 10.1108/JMHTEP-03-2013-0009

are

Mahlke, C. I. Krämer. U. M., Becker, T and Bock, T. (2014), "Peer support in mental health services", Current Opinions Psychiatry, Vol. 27 No. 4, pp. 276-281. http://dx.doi.org/10.1108/MHRJ-04-2014-0014

McLean, J., Biggs, H., Whitehead, I., Pratt, R., Maxwell, M., (2009). Evaluation Of The Delivering For Mental Health Peer Support Worker Pilot Scheme Scottish Government Social Research, Edinburgh 
Nesta, (2015). Peer Support and What it is and does it work. National Voices, London

Ockwell, C., (2012),"Challenges and triumphs: developing an inpatient peer support project", The Journal of Mental Health Training, Education and Practice, Vol. 7 No. 2, pp. 94 - 100. http://dx.doi.org/10.1108/17556221211236501

Pitt V., Lowe D., Hill S., Prictor M., Hetrick S. E., Ryan R. and Berends, L. (2013), Consumer-providers of care for adult clients of statutory mental health services (Review), The Cochrane Collaboration, issue 3 The Cochrane Collaboration. JohnWiley \& Sons

Repper ,J.. and Carter, T. (2011). A review of the literature on peer support in mental health services. Journal of Mental Health, Vol. 20 No. 4, pp. 392-411. DOI: 10.3109/09638237.2011.583947

Repper, J. and Watson, E. (2012), "A year of peer support in Nottingham: lessons learned", The Journal of Mental Health Training, Education and Practice, Vol. 7 No. 2, pp.70-78.

Roberts, G. and Boardman, J. (2014), "Becoming a recovery-oriented practitioner", Advances in psychiatric treatment, Vol. 20 No. 1, pp. 37-47. doi: 10.1192/apt.bp.112.010652

Simpson, A., Flood, C., Rowe, J., Quigley, J., Henry, S., Hall, C., Evans, R., Sherman, P. and Bowers, L. (2014). Results of a pilot randomised controlled trial to measure the clinical and cost effectiveness of peer support in increasing hope and quality of life in mental health. BMC Psychiatry, Vol. 14 No. 30, pp.1-14. http://www.biomedcentral.com/1471-244X/14/30

Sledge, W. H., Lawless M, Sells D, Weiland, M., O'Connell M. J. and Davidson, L. "Effectiveness of peer support in reducing readmissions of persons with multiple psychiatric hospitalizations" Psychiatric Services, Vol. 62 No. 5, pp. 541-544.

Walker, G. and Bryant, W. (2013), "Peer Support in Adult Mental Health Services:

A Metasynthesis of Qualitative Findings", Psychiatric Rehabilitation Journal, Vol. 36 No. 1, pp. 28-34 DOI 1095-158X/13/\$12.00

Wrobleski, T., Walker, G., Jarus-Hakak, A., and Suto, M. J. (2015), "Peer support as a catalyst for recovery: A mixed-methods study" Canadian Journal of Occupational Therapy, Vol. 82 No. 1, pp. 64-73 DOI: 10.1177/0008417414551784 
